\title{
Analysis of QTLs for Reproductive Development and Seed Quality Traits in Soybean using Recombinant Inbred Lines
}

\author{
Satoshi Watanabe, Teuku Tajuddin'), Naoki Yamanaka ${ }^{2}$, Masaki Hayashi and Kyuya Harada* \\ Graduate School of Science and Technology, Chiba University, 648 Matsudo, Chiba 271-8510, Japan \\ 1) Present address: Center for the Assessment and Application of Biotechnology, 630 Building Puspiptek, Serpong, Tangerang 15314, \\ Indonesia \\ 2) Present address: Biological Resources Division, Japan International Research Center for Agricultural Sciences, 1-1 Ohwashi, \\ Tsukuba 305-8686, Japan
}

Soybean (Glycine max (L.) Merrill) is the most important leguminous crop in the world due to the high contents of protein and oil, and accumulation of various physiologically active substances. However, most of the genomic and economic traits in soybean are quantitative, controlled by multiple genes and easily affected by environmental conditions. Based on recombinant inbred lines $\left(F_{8}\right)$, a genetic linkage map with 177 RFLP, 150 SSR, 28 AFLP markers and 5 phenotypic markers was constructed. The map covered a distance of $2663.6 \mathrm{cM}$ of the soybean genome comprising 20 linkage groups. The average distance between two adjacent marker loci was $7.89 \mathrm{cM}$. In this population, we detected thirty-nine QTLs for all the reproductive development and seed quality traits investigated, that is, three for flowering time (FT1-3), four for maturity $(H A V 1-4)$, three for reproductive period $(R P 1-3)$, three for seed hardness (RAS1-3), five for viability of seed (VIS1-5), four for germination rate of seed (GRS1-4), five for water absorbability of seed (WAS1-5) and twelve QTLs for seed weight (SWE1-6 and SWH1-6). Out of these QTLs, twenty-eight were detected in nearly the same regions of the linkage map by both IM (interval mapping) and CIM (composite interval mapping) analysis. The proportion of variance explained of these QTLs ranged from $3.4 \%$ to $67.1 \%$. Epistatic interactions were detected among various QTLs. Especially there was a strong interaction among the effects of $F T 1$ and $F T 2$, and $F T 1$ and $F$ T3. Multiple correlation coefficients between $F T 1$ and $F T 2$, and $F T 1$ and $F T 3$ accounted for $79.6 \%$ and $\mathbf{7 4 . 1} \%$ of the phenotypic variation of flowering time, respectively.

Key Words: Glycine $\max$ (L.) Merrill, linkage map, quantitative trait loci, recombinant inbred lines, reproductive development, seed quality.

Communicated by M. Ishimoto

Received May 31, 2004. Accepted August 17, 2004.

*Corresponding author (e-mail: haradaq@faculty.chiba-u.jp)

\section{Introduction}

Soybean (Glycine max (L.) Merrill) is the most important leguminous crop in the world due to its high content of high quality protein for food and feed, and a capacity of oil production for food and industrial materials. Recently, many physiologically active substances have been identified in soybean seeds and soybean has been considered to be a very important crop for human health.

The traits associated with reproductive development including flowering time, maturity and reproductive period are related to the adaptation of soybean to growth environments and they eventually affect the yield. Characteristics of soybean seeds are related to the productivity and processing of foods including Tofu, Miso and Natto.

These quantitative traits are controlled by multiple genes and are easily affected by environmental conditions. Genetic analysis of quantitative traits could be effectively performed by the use of QTL (Quantitative Trait Locus) analysis by constructing a linkage map covering a large region of the genome based on RILs (Recombinant Inbred Lines). The advantage of using a RIL population is that replicated experiments at different locations and/or times could be carried out and enable us to evaluate environmental effects.

QTL analyses in soybean were reported for the flowering time (Mansur et al. 1993, Orf et al. 1999a, Yamanaka et al. 2000, 2001), maturity (Mansur et al. 1996, Lark et al. 1994, 1995), seed weight (Mansur et al. 1993, Maughan et al. 1996, Orf et al. 1999b), seed size (Hoeck et al. 2003), lipid and protein contents (Diers et al. 1992, Lee et al. 1996, Brummer et al. 1997, Tajuddin et al. 2002, 2003) and seed hardness (Keim et al. 1990). However there are only a few reports on QTL analysis for the traits associated with reproductive development and seed quality based on linkage maps of RILs with a high coverage of the soybean genome.

The objectives of our study were to construct a genetic linkage map covering a large region of the soybean genome using RILs and to analyze QTLs and their interactions associated with reproductive development and seed quality traits. 


\section{Materials and Methods}

\section{Plant materials and phenotypic investigations}

A population of recombinant inbred lines (RILs) was derived from a cross between the soybean (Glycine max) cultivar Misuzudaizu and the line Moshidou Gong 503 for the construction of a linkage map and QTL analysis. Misuzudaizu is a cultivar developed at Nagano Chusin Agricultural Experiment Station in Japan, while Moshidou Gong 503 is a weedy line originating from Jinlin province, China that was obtained from the germplasm collection of the National Institute of Agrobiological Resources, Tsukuba, Japan. A total population of 156 RILs developed by single seed descent from the $\mathrm{F}_{2}$ population was planted in the field of Matsudo campus, Chiba University, Japan, during the summer of 1998 to obtain $\mathrm{F}_{8}$ seeds. Approximately 15 plants and 8 plants per line were used in 1999 and 2001, respectively for phenotypic investigations. The characteristics of these traits and the measurement criteria are summarized in Table 1. Flowering time $(F T)$ and seed weight were evaluated in 1999 and 2001. To determine the flowering time, maturity $(H A V)$ and reproductive period $(R P)$, the RIL population was sowed on June 5, 1999 in the Kashiwa field and on May 19, 2001 at the Matsudo campus of Chiba University and cultivated under standard conditions. For the characterization of the seeds, 50 seeds per line sterilized with $70 \%$ ethanol were kept on a wet filter paper in the dark at $25^{\circ} \mathrm{C}$. After 24 hours, the rate of seeds that absorbed water $(R A S)$ and weight of the seeds that absorbed water $(W A S)$ were determined, and after 4 days, the rate of germination $(G R S)$ was evaluated. For the determination of the viability of seeds $(V I S)$, the seeds that did not absorb water were scarified. Average seed weight (SWE) using 15 seeds per line was calculated in 1999 and average values of two measurements of hundred seed weight $(S W H)$ were obtained in 2001.

The qualitative phenotypic characteristics including flower color $(W)$, pubescence color $(T)$, stem growth habit $(D t 1)$, seed color $(I)$ and presence of $11 \mathrm{~S}$ globulin subunit A4 (Gly-3) determined by SDS-PAGE were scored and used as phenotypic markers.

\section{Analysis of DNA polymorphisms}

Genomic DNA was extracted from the leaves of each selected individual by the CTAB method (Murray and Thompson 1980). For RFLP analysis, the DNA was digested with eight restriction enzymes, ApaI, BamHI, BglII, DraI, EcoRI, EcoRV, HindIII and KpnI. Electrophoresis, Southern blotting and hybridization procedures were performed as previously described by Yamanaka et al. (2000). SSR markers developed by USDA (Cregan et al. 1999), Dupont Corporation and Chiba University (Hossain et al. 2000) were used and conditions for PCR, electrophoresis and detection of polymorphisms were the same as those described previously (Tajuddin et al. 2003). The AFLP reaction was performed according to the method of Vos et al. (1995) with a slight modification using a combination of restriction enzymes EcoRI and MseI and $100 \mathrm{ng}$ of genomic DNA as a template for the reaction. Details of this method were described previously (Hayashi et al. 2001).

\section{Construction of linkage map}

From the linkage map constructed based on the $F_{2}$ population, which was the original population of RILs in this study, RFLP and SSR markers were selected for even distribution on all the linkage groups. The genotypes of these markers were scored against 156 progenies of the $\mathrm{F}_{8}$ generation to construct a RIL linkage map. For the analysis, the data for heterozygous genotypes at all the genetic loci, were omitted, since the computer programs could not handle such data during the calculation. The linkage map was constructed by using the computer program MAPMAKER/EXP 3.0 (Lincoln et al. 1993) at a minimum given log of likelihood

Table 1. List of investigated traits and measurement criteria

\begin{tabular}{|c|c|c|c|c|}
\hline Trait & $\begin{array}{c}\text { Assigned } \\
\text { name of QTL }\end{array}$ & Year & $\begin{array}{c}\text { Subset of } \\
\text { measurement }\end{array}$ & Measurement method or criteria \\
\hline Flowering time & $F T$ & $\begin{array}{l}1999 \\
2001\end{array}$ & $\begin{array}{l}15 \text { plants/line } \\
8 \text { plants/line }\end{array}$ & $\begin{array}{l}\text { Days from sowing to first flowering (over } 50 \% \\
\text { plants in the same line had flowered) }\end{array}$ \\
\hline Maturity & $H A V$ & 1999 & 15 plants/line & $\begin{array}{l}\text { Days from sowing to harvest (over } 50 \% \text { plants } \\
\text { in the same line had matured) }\end{array}$ \\
\hline Reproductive period & $R P$ & 1999 & 15 plants/line & Maturity minus flowering time \\
\hline Seed hardness & $R A S$ & 2001 & 50 seeds/line & $\begin{array}{l}\text { Rates (percentage) of number of seeds that } \\
\text { absorbed water per number of all seeds }\end{array}$ \\
\hline Viability of seed & $V I S$ & 2001 & 50 seeds/line & $\begin{array}{l}\text { Rates of germinated seeds per number of } \\
\text { absorbed seeds }\end{array}$ \\
\hline Germination rate & $G R S$ & 2001 & 50 seeds/line & $\begin{array}{l}\text { Rates of germinated seeds per number of all } \\
\text { seeds }\end{array}$ \\
\hline Water absorbability of seed & $W A S$ & 1999 & 15 seeds/line & $\begin{array}{l}\text { Weight of seeds that absorbed water per dry } \\
\text { seed weight }\end{array}$ \\
\hline \multirow[t]{2}{*}{ Seed weight } & $S W E$ & 1999 & 15 seeds/line & Average seed weight of single seeds \\
\hline & $S W H$ & 2001 & Hundred seed weight & $\begin{array}{l}\text { Average seed weight calculated from hundred } \\
\text { seed weight with two replications }\end{array}$ \\
\hline
\end{tabular}


(LOD)-value of 3.0 as the threshold for grouping the genetic markers.

\section{QTL analysis and statistical analysis}

The presence of QTLs and their effects were calculated by interval mapping (IM) (Lander and Botstein 1989) and composite interval mapping (CIM) analysis (Zeng 1993). Both IM and CIM methods were applied using QTL Cartographer version 2.0 (Basten et al. 2001). A minimum LODvalue of 2.0 was selected to confirm the presence of a QTL in a given genomic region. When the peaks were detected only by IM analysis, we considered these to be false QTLs and they were not located on the linkage map. The LODvalue peaks detected by both IM and CIM analysis or by only CIM analysis were used to estimate the most likely QTL positions on the linkage map. In addition, two-factor analysis of variance (Lark et al. 1994, 1995) was used to detect epistatic interaction between all the pairs of QTLs. Multiple regression analysis was used to estimate the interaction effects between QTLs and additive effect of each QTL. To estimate each effect and the proportion of variance explained, the genotype of each QTL was determined based on the nearest marker. For statistical analysis other than QTL analysis, we used Excel program with windows operation system for the calculation. The equation for multiple regression analysis was as follows.

$$
Y_{i}=\mu+\mathrm{X}_{1 i} a+\mathrm{X}_{2 i} b+\mathrm{X}_{3 i} i_{A B}+\varepsilon_{i}
$$

where $Y_{i}$ : phenotypic value of each line $i, \mu$ : mean of phenotypic value, $a$ : additive effect of QTL1, $b$ : additive effect of QTL2, $i_{A B}$ : effect of interaction between QTL1 and QTL2, $\varepsilon_{i}$ : error. $\mathrm{X}_{1}, \mathrm{X}_{2}$ and $\mathrm{X}_{3}$ denote the variables based on the genotype of QTL1 and QTL2, being 1, 1, 1, for A, A, 1, -1, -1 , for A, B, $-1,1,-1$, for B, A, $-1,-1,1$, for B, B. A and B refer to the Misuzudaizu allele and Moshidou Gong 503 allele, respectively. Least square estimation was used to calculate each parameter. $\mathrm{R}^{2}$ indicates the proportion of variance explained by the combination of these effects. The test of interaction between two QTLs was evaluated by the F-value.

\section{Results}

\section{Phenotypic investigations of quantitative traits}

All the quantitative traits investigated in this study showed a continuous phenotypic distribution in the RIL population (Fig. 1). The results indicated that these traits were quantitative traits controlled by multiple loci. The frequency distribution of the seed weight ( $S W E$ and $S W H$ ) and water absorbability of seed $(W A S)$ fitted to a normal distribution ( $p>0.05$ ) when tested by goodness of fit (Gomez and Gomez 1984) (data not shown). Furthermore, the phenotypic distribution of the flowering time (FT), maturity (HAV), reproductive period $(R P)$, viability of seed $(V I S)$ and water absorbability of seed (WAS), included transgressive segregants compared to parents, indicating that at least one of the parents carried the alleles for the opposite effect, while the parental phenotypic values of the seed weight were located at both ends of the distribution.

The value of broad-sense heritability for the flowering time which was calculated based on the phenotypic correlation between the data of 1999 and 2001 was 0.96, indicating that this trait was characterized by a high environmental stability. In contrast, the low value of the heritability of seed weight, 0.55 , indicated that this trait was more readily affected by environmental conditions compared to the flowering time.

\section{Construction of linkage map based on RILs}

Based on the RIL $F_{8}$ generation, a genetic linkage map with 177 RFLP, 150 SSR, 28 AFLP markers and 5 phenotypic markers (total 360) was constructed (Fig. 2). The map covered a distance of $2663.6 \mathrm{cM}$ of the soybean genome using the Kosambi function, comprising 20 linkage groups. This map showed the same order of most of the markers as that in the $\mathrm{F}_{2}$ linkage map (Yamanaka et al. 2001) and integrated linkage map (Cregan et al. 1999, Song et al. 2004). The average distance between two adjacent marker loci was $7.89 \mathrm{cM}$.

In this population, the segregation ratio of each genetic locus coincided with the Mendelian segregation ratio. However, some of the loci showed a segregation distortion for the expected segregation ratio of $1: 1$. These loci were located on the linkage map (Fig. 2). The segregation distortion in the region, especially on the linkage groups $\mathrm{A} 1, \mathrm{~L}$ and $\mathrm{M}$, may be due to the factors that had influenced the allelic distribution during the process of generation of this population. Most of the co-dominant markers had a few heterozygous alleles and these rates were likely to fit to the theoretical expected rates (data not shown). The mean and range of allelic frequency of Misuzudaizu in this population were 50.9 \pm 7.4 $\%$, and $33.2 \%$ to $71.5 \%$, respectively.

\section{QTL analysis for quantitative traits}

For all the traits, the major effective QTLs were detected, and the positions of all the QTLs were located on the linkage map (Fig. 2). The information about the position and effects of these QTLs is summarized in Table 2. A total of 39 QTLs were identified for 8 traits determined in this study. Twenty-eight QTLs were detected in nearly the same regions of the linkage map by both IM and CIM analysis.

For the flowering time $(F T)$, three QTLs were detected generally based on the phenotypic data obtained during the two-year period. FT1 and FT2 could be detected by both IM and CIM analysis, while the peak of FT3 could be detected by CIM analysis only. The phenotypic variance explained by FT1 for the flowering time was $67.4 \%$ and it was the highest value for all the QTLs detected. For the maturity $(H A V)$ and the reproductive period $(R P)$, four QTLs $(H A V 1-4)$, and three QTLs $(R P 1-3)$ were detected, respectively. QTLs for the above characters, FT1, HAV1 and RP2 were detected close together in the region of LG C2. Similar associations 

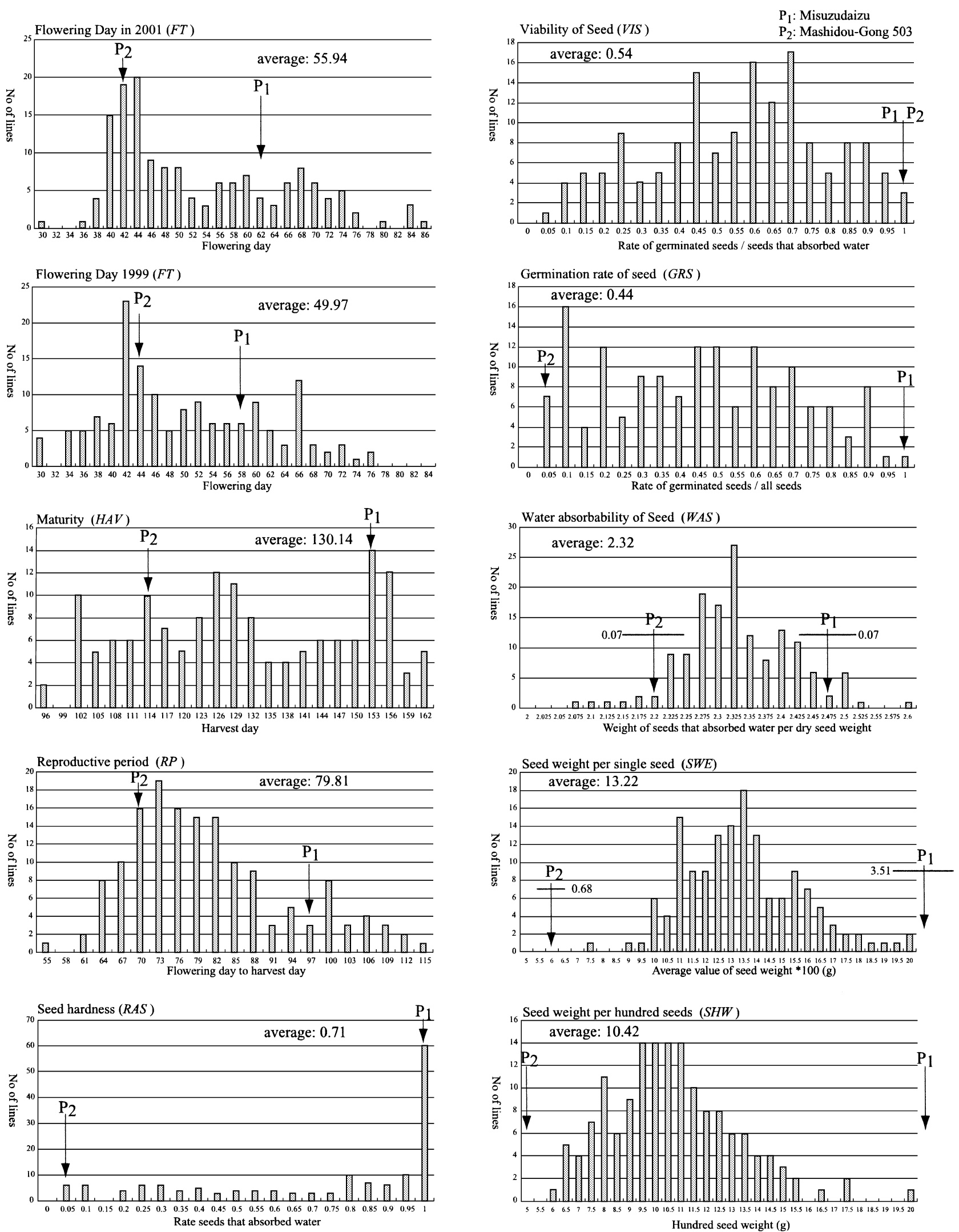

Fig. 1. Frequency distribution of quantitative traits in the soybean RIL population derived from a cross between Misuzudaizu and Moshidou Gong 503. Parental values of phenotype are indicated on the figure by arrows $\left(\mathrm{P}_{1}\right.$ : Misuzudaizu $\mathrm{P}_{2}$ : Moshidou Gong 503). Horizontal bars and numbers indicate standard deviations in the parents. The absence of bars indicates that these traits were not evaluated based on individual plants in the same line but based on each line. Average value of each graph shows the mean of the RIL population. 

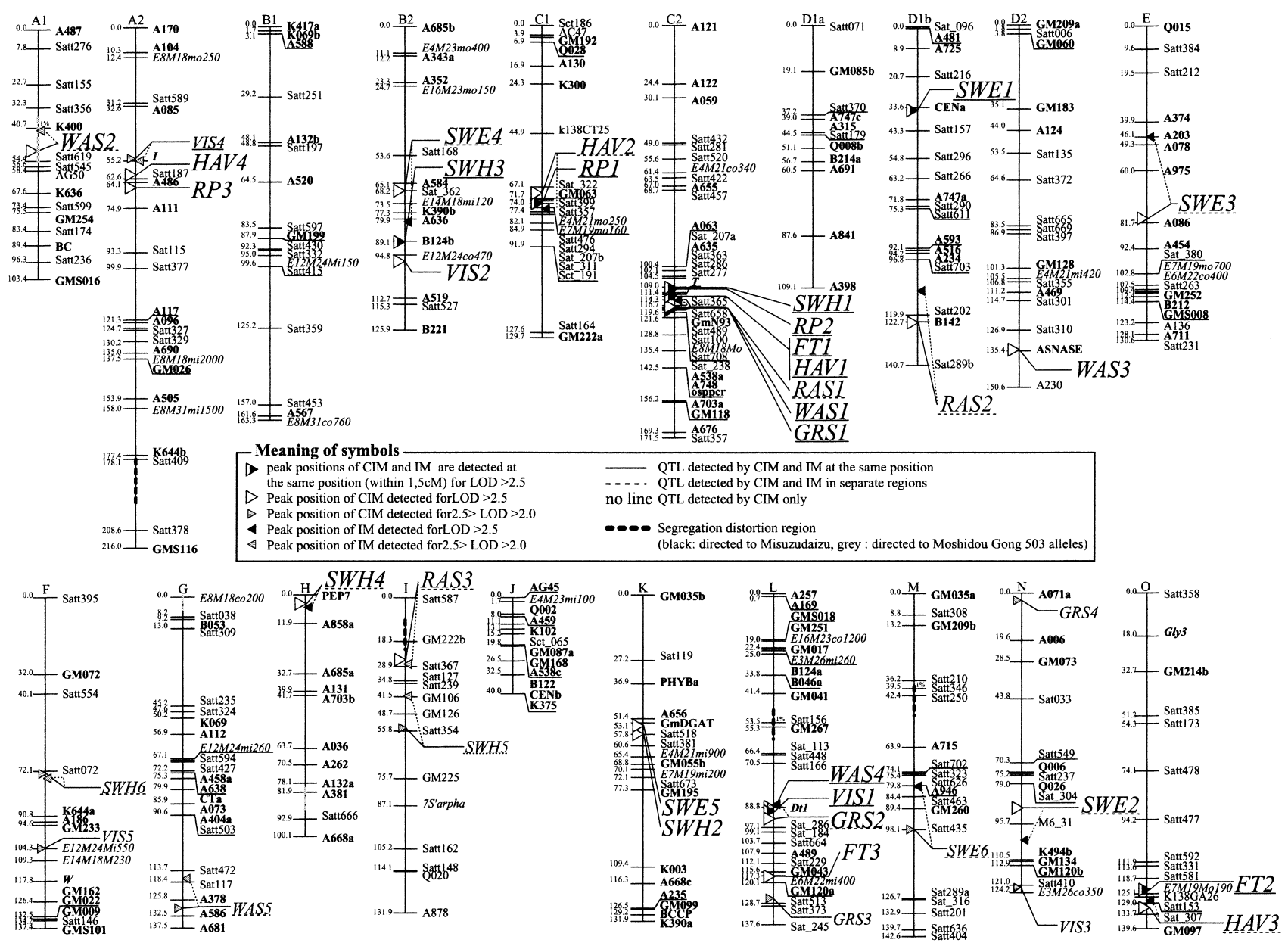

Fig. 2. Linkage map of soybean RIL population generated from Misuzudaizu and Moshidou Gong 503 and locations of identified QTLs for agronomic traits. RI model of MAPMAKER 3.0 was used. The names of all the linkage groups were assigned by comparison with the linkage map of Cregan et al. (1999). Arrowheads show the location of the QTLs and classified criteria are summarized in the box of the figure. The numbers on the left-hand side of each linkage group indicate the genetic distance from the top of each linkage group using the Kosambi function. Markers are denoted as follows: RFLP markers, bold letters; SSR markers, normal letters; AFLP markers, italic letters; phenotypic markers, bold italics.

were observed between FT2 and HAV3 (on LG O), RP1 and $H A V 2$ (LG C1), and, RP3 and HAV4 (LG A2).

We detected three QTLs for seed hardness $(R A S)$ at the proximal position by both IM and CIM analysis (RAS1-3). As shown in Figure1, the phenotypic distribution was highly skewed, and appeared to follow a poisson distribution. The phenotypic data of seed hardness were subject to arc sine transformation, but the results of QTL analysis were identical between raw and transformed data.

For the viability of seed (VIS), five QTLs (VIS1-5) were detected. Two out of the five QTLs were located close to the phenotypic markers $D t 1$ and $I$, respectively. The most effective QTL was located on Dt1 with a contribution level of variance of $18.5 \%$. The other QTLs showed a contribution rate of variance of around $3.8 \%$ to $5.9 \%$.

For the germination rate of seed, the major QTL (GRS1) and second effective QTL (GRS2) were identified at the same location as that of RAS1 and VIS1, respectively, while other QTLs (GRS3-4) were detected at different loci from those of $R A S$ and $V I S$.

Although we expected that water absorbability of seed would be associated with seed hardness, these two traits showed a low correlation $\left(r^{2}=0.05\right)$. The QTLs for water absorbability of seed were detected at different loci in the soybean genome except for WAS1 on LG C2. Although WAS1 was located at almost the same position as that of $R A S 1$, it showed a low contribution rate for phenotypic variance (14.1\%).

For the seed weight ( $S W E$ and $S W H$ ), we analyzed the data sets collected over a two-year period. However, the QTLs detected did not correspond to each other. Twelve QTLs were detected and indicated on the linkage map. Especially among all the detected QTLs, SWE4 and SWH3, $S W E 5$ and $S W H 2$ were located in nearly the same regions on LG B2 and K, respectively. The proportion of phenotypic variance explained by individual QTLs for seed weight ranged from $4 \%$ to $12 \%$. 
Table 2. Summary of detected QTLs, with their positions and effects

\begin{tabular}{|c|c|c|c|c|c|c|c|c|c|c|}
\hline QTL & LG & Analysis & First marker & $(\mathrm{cM})$ & Second marker & $(\mathrm{cM})$ & $\begin{array}{l}\text { QTL positon } \\
\text { (cM) }\end{array}$ & LOD & $\begin{array}{l}\text { Additive } \\
\text { effect }\end{array}$ & $\mathrm{R}^{2}(\%)$ \\
\hline \multirow[t]{2}{*}{ FT1 } & $\mathrm{C} 2$ & CIM & Satt365* & 113.0 & Satt658 & 114.3 & 113.0 & 50.5 & 9.87 & 62.1 \\
\hline & & IM & $T$ & 111.9 & Satt365 & 113.0 & 112.9 & 37.5 & 10.18 & 67.4 \\
\hline \multirow[t]{2}{*}{$F T 2$} & $\mathrm{O}$ & CIM & Satt581 & 118.7 & E7M19Mo190D* & 125.1 & 123.7 & 16.5 & -4.32 & 12.0 \\
\hline & & $\mathrm{IM}^{1)}$ & & & & & 123.7 & 3.6 & -4.19 & 11.4 \\
\hline FT3 & $\mathrm{L}$ & CIM & E6M22mi400* & 117.3 & GM120a & 120.1 & 117.3 & 7.7 & 2.66 & 4.5 \\
\hline \multirow[t]{2}{*}{ HAVI } & $\mathrm{C} 2$ & CIM & $T$ & 111.9 & Satt365* & 113.0 & 112.9 & 30.6 & 13.29 & 51.2 \\
\hline & & IM & & & & & 112.9 & 23.4 & 13.22 & 51.3 \\
\hline \multirow[t]{2}{*}{$H A V 2$} & $\mathrm{C} 1$ & CIM & Sat_322* & 67.1 & GM063 & 71.7 & 69.1 & 4.9 & 4.64 & 6.2 \\
\hline & & IM & E7M19mo160 & 75.7 & Satt476 & 77.4 & 76.7 & 2.3 & 4.81 & 6.8 \\
\hline \multirow[t]{2}{*}{$H A V 3$} & $\mathrm{O}$ & CIM & Satt153 & 129.0 & Sat_307* & 133.7 & 133.0 & 4.5 & -4.28 & 5.2 \\
\hline & & IM & K138GA26 & 126.5 & Satt153 & 129.0 & 128.5 & 2.3 & -4.86 & 6.9 \\
\hline HAV4 & A2 & CIM & $I$ & 55.2 & Satt187* & 62.6 & 59.2 & 3.4 & -4.05 & 4.7 \\
\hline \multirow[t]{2}{*}{$R P 1$} & $\mathrm{C} 1$ & CIM & E7M19mo160* & 75.7 & Satt476 & 77.4 & 75.7 & 4.6 & 4.09 & 10.0 \\
\hline & & $\mathrm{IM}$ & & & & & 75.7 & 3.5 & 4.01 & 10.0 \\
\hline \multirow[t]{2}{*}{$R P 2$} & $\mathrm{C} 2$ & CIM & Satt286* & 109.0 & Satt277 & 111.4 & 110.0 & 4.4 & 4.02 & 10.0 \\
\hline & & IM & & & & & 110.0 & 3.5 & 4.13 & 10.6 \\
\hline$R P 3$ & $\mathrm{~A} 2$ & CIM & A486 & 64.1 & A111* & 74.9 & 70.1 & 3.3 & -3.82 & 8.8 \\
\hline \multirow[t]{2}{*}{$R A S 1$} & $\mathrm{C} 2$ & CIM & Satt489* & 117.0 & Satt100 & 117.3 & 117.0 & 14.0 & 0.17 & 26.0 \\
\hline & & IM & $T$ & 111.9 & Satt365 & 113.0 & 112.9 & 12.0 & 0.18 & 30.0 \\
\hline \multirow[t]{2}{*}{$R A S 2$} & $\mathrm{D} 1 \mathrm{~b}$ & CIM & B142* & 122.7 & Sat $289 b$ & 140.7 & 122.7 & 6.3 & 0.11 & 10.6 \\
\hline & & IM & Satt703 & 96.8 & Satt202 & 119.9 & 111.8 & 6.5 & 0.18 & 30.2 \\
\hline \multirow[t]{2}{*}{ RAS3 } & I & CIM & GM222b & 18.3 & Satt367* & 28.9 & 25.3 & 3.0 & 0.08 & 6.1 \\
\hline & & IM & & & & & 28.3 & 2.2 & 0.09 & 6.8 \\
\hline \multirow[t]{2}{*}{ VIS1 } & $\mathrm{L}$ & CIM & $D t 1^{*}$ & 88.8 & Sat_286 & 97.1 & 90.8 & 7.51 & -0.10 & 18.5 \\
\hline & & $\mathrm{IM}$ & & & & & 89.8 & 6.9 & -0.10 & 20.0 \\
\hline VIS2 & B2 & CIM & E12M $24 \operatorname{co} 470 *$ & 94.8 & A519 & 112.7 & 96.8 & 2.5 & 0.06 & 5.9 \\
\hline VIS3 & $\mathrm{N}$ & CIM & Satt $410^{*}$ & 121.0 & E3M $26 \operatorname{co} 350$ & 124.2 & 122.0 & 2.2 & -0.05 & 4.7 \\
\hline \multirow[t]{2}{*}{ VIS4 } & $\mathrm{A} 2$ & CIM & A085 & 32.6 & $I^{*}$ & 55.2 & 54.6 & 2.2 & 0.05 & 4.8 \\
\hline & & IM & $I$ & 55.2 & Satt187 & 62.6 & 55.2 & 2.0 & 0.06 & 5.9 \\
\hline VIS5 & $\mathrm{F}$ & CIM & E12M24Mi550D* & 104.3 & E14M18M230D & 109.3 & 104.3 & 2.0 & -0.05 & 3.8 \\
\hline \multirow[t]{2}{*}{ GRS1 } & $\mathrm{C} 2$ & CIM & E8M18Mo1000A* & 117.6 & Satt708 & 119.6 & 117.6 & 14.9 & 0.14 & 29.5 \\
\hline & & IM & & & & & 117.6 & 10.9 & 0.13 & 27.6 \\
\hline \multirow[t]{2}{*}{$G R S 2$} & $\mathrm{~L}$ & CIM & $D t 1$ & 88.8 & Sat_286* & 97.1 & 95.8 & 7.2 & -0.10 & 13.6 \\
\hline & & $\mathrm{IM}$ & Satt166 & 70.5 & $D t \overline{1}$ & 88.8 & 87.5 & 5.2 & -0.10 & 15.6 \\
\hline GRS3 & $\mathrm{L}$ & CIM & GM120a & 120.1 & Satt513* & 128.7 & 127.1 & 3.5 & 0.07 & 6.8 \\
\hline GRS4 & $\mathrm{N}$ & CIM & GM073* & 28.5 & Sat033 & 43.8 & 28.5 & 2.2 & -0.05 & 3.4 \\
\hline \multirow[t]{2}{*}{ WAS1 } & $\mathrm{C} 2$ & CIM & Satt658* & 114.3 & GmN93 & 116.7 & 115.3 & 6.4 & -0.03 & 14.1 \\
\hline & & IM & & & & & 116.3 & 5.5 & -0.04 & 16.7 \\
\hline$W A S 2$ & $\mathrm{~A} 1$ & CIM & K400 & 40.7 & Satt619* & 54.4 & 47.7 & 3.8 & 0.03 & 9.3 \\
\hline & & IM & & & & & 41.7 & 2.2 & 0.02 & 6.8 \\
\hline$W A S 3$ & D2 & CIM & Satt310 & 126.9 & Asnase* & 135.4 & 134.9 & 3.5 & 0.02 & 7.6 \\
\hline WAS4 & $\mathrm{L}$ & CIM & $D t 1^{*}$ & 88.8 & Sat_286 & 97.1 & 88.8 & 2.7 & 0.02 & 5.4 \\
\hline & & IM & Satt166 & 70.5 & $D t \overline{1}$ & 88.8 & 87.5 & 3.9 & 0.03 & 12.5 \\
\hline WAS5 & G & CIM & A378 & 125.8 & A586* & 132.5 & 130.8 & 2.3 & -0.02 & 5.5 \\
\hline & & $\mathrm{IM}$ & Satt472 & 113.7 & Sat117 & 118.4 & 116.7 & 2.3 & -0.02 & 7.9 \\
\hline SWE1 & D1b & CIM & $\mathrm{CENa}^{*}$ & 33.6 & Satt157 & 43.3 & 34.6 & 5.4 & 0.80 & 12.0 \\
\hline & & IM & & & & & 35.6 & 4.1 & 0.85 & 13.5 \\
\hline SWE2 & $\mathrm{N}$ & CIM & Sat_304 & 79.0 & M6_31* & 95.7 & 88.0 & 3.8 & 0.74 & 10.3 \\
\hline & & IM & M6_31 & 95.7 & $\mathrm{~K} 494 \mathrm{~b}$ & 110.5 & 100.7 & 2.9 & 0.80 & 12.0 \\
\hline SWE3 & $\mathrm{E}$ & CIM & A975* & 60.0 & A086 & 81.7 & 60.0 & 3.3 & 0.60 & 6.6 \\
\hline & & IM & A203 & 46.1 & A078 & 49.3 & 46.1 & 3.3 & 0.72 & 9.7 \\
\hline SWE4 & B2 & CIM & Sat_362* & 68.2 & E14M18mi120 & 73.5 & 68.2 & 3.2 & 0.59 & 6.4 \\
\hline & & IM & A $\overline{3} 6$ & 79.9 & $\mathrm{~B} 124 \mathrm{~b}$ & 89.1 & 82.9 & 3.1 & 0.76 & 10.8 \\
\hline SWE5 & K & CIM & GmDGAT* & 53.1 & Satt518 & 57.8 & 54.1 & 3.1 & 0.59 & 6.4 \\
\hline SWE6 & M & CIM & Satt $435^{*}$ & 98.1 & Sat289a & 126.7 & 98.1 & 2.3 & 0.46 & 4.0 \\
\hline & & $\mathrm{IM}$ & A946 & 79.8 & Satt463 & 84.4 & 79.8 & 2.9 & 0.69 & 8.9 \\
\hline
\end{tabular}


Table 2. (continued)

\begin{tabular}{|c|c|c|c|c|c|c|c|c|c|c|}
\hline QTL & LG & Analysis & First marker & $(\mathrm{cM})$ & Second marker & (cM) & $\begin{array}{l}\text { QTL positon } \\
\text { (cM) }\end{array}$ & LOD & $\begin{array}{c}\text { Additive } \\
\text { effect }\end{array}$ & $\mathrm{R}^{2}(\%)$ \\
\hline \multirow[t]{2}{*}{ SWH1 } & $\mathrm{C} 2$ & CIM & Satt286* & 109.0 & Satt277 & 111.4 & 109.0 & 3.8 & 0.71 & 7.7 \\
\hline & & IM & & & & & 109.0 & 5.3 & 0.95 & 14.5 \\
\hline $\mathrm{SWH} 2$ & K & CIM & Satt518* & 57.8 & Satt381 & 60.6 & 57.8 & 3.2 & 0.61 & 5.8 \\
\hline \multirow[t]{2}{*}{ SWH3 } & B2 & CIM & B124b* & 89.1 & E12M24co470 & 94.8 & 89.1 & 3.1 & 0.62 & 6.1 \\
\hline & & IM & & & & & 90.1 & 2.5 & 0.70 & 7.8 \\
\hline \multirow[t]{2}{*}{ SWH4 } & $\mathrm{H}$ & CIM & PEP7* & 0.0 & A858a & 11.9 & 4.0 & 2.9 & 0.69 & 7.4 \\
\hline & & IM & & & & & 7.0 & 3.3 & 0.89 & 12.7 \\
\hline \multirow[t]{2}{*}{ SWH5 } & I & CIM & GM126 & 48.7 & Satt354* & 55.8 & 54.7 & 2.2 & 0.55 & 4.8 \\
\hline & & IM & GM106 & 41.5 & GM126 & 48.7 & 41.5 & 2.0 & 0.60 & 5.9 \\
\hline \multirow[t]{2}{*}{ SWH6 } & F & CIM & Satt072* & 72.1 & K644a & 90.8 & 73.1 & 2.1 & 0.51 & 4.2 \\
\hline & & IM & & & & & 75.1 & 2.1 & 0.71 & 8.0 \\
\hline
\end{tabular}

Each QTL was detected between the first marker and the second one. Each position shows the distance from the top of each linkage group. Each LG corresponds to the linkage group shown in Figure 1. Additive effects of each QTL are those of Misuzudaizu allele in contrast to Moshidou Gong 503 allele. $\mathrm{R}^{2}$ shows the proportion of the variance explained by each QTL. Two data were presented when a QTL was detected by IM (interval mapping) and CIM (composite interval mapping) analysis.

1) The same marker and position detected by IM are omitted in each column. Asterisk above the markers show the nearest marker from each QTL and the genotypes of these markers were used for statistical analysis.

\section{Interaction analysis between detected QTLs}

Based on the genotype of the nearest marker to each QTL (Table 2), we analyzed the interaction between QTLs, using two-way classification of ANOVA. Nine out of seventy-one combinations of QTLs displayed interactions between QTL loci. To estimate the additive effects, effects of epistasis, and contribution rates for phenotypic variance, we used a multiple regression analysis (Table 3 and materials and methods).

For the QTLs of the flowering time, all the combinations of QTLs showed epistasis. These results indicated that there was a strong interaction among the effects of FT1, FT2 and FT3. When the genotype of the FTI locus was fixed, the differences between $F T 2$ genotypes were 12.4 days (with Misuzudaizu genotype FT1/FT1) and 2.3 days (with Moshidou Gong 503 genotype $f t 1 / f t 1$ ), respectively. Similarly in the FT3 genotype, the differences were 9.3 days (with Misuzudaizu genotype FT1/FT1) and 0.5 days (with Moshidou Gong 503 genotype $f t 1 / f t 1$ ), respectively. Estimated effect of each QTL corresponded to the QTL analysis, and multiple correlation coefficients of FT1 and FT2, and FT1 and FT3 accounted for $79.6 \%$ and $74.1 \%$ of the phenotypic variance of flowering time, respectively.

Interaction between $H A V 1$ and $H A V 3$ was identical with that of $F T 1$ and $F T 2$. Moreover, other combinations of QTLs also showed epistatic interaction, that is $R P 1$ and $R P 2$,

Table 3. Analysis of interaction between QTLs detected by multiple regression analysis

\begin{tabular}{|c|c|c|c|c|c|c|c|c|c|c|c|c|c|c|}
\hline QTL1 & $\begin{array}{c}\text { Proximal } \\
\text { marker }\end{array}$ & QTL2 & $\begin{array}{c}\text { Proximal } \\
\text { marker }\end{array}$ & $\mu$ & $a$ & $b$ & $i_{\mathrm{AB}}$ & $\begin{array}{l}\mathrm{R}^{2} \\
(\%)\end{array}$ & F-value & probability & $\mathrm{AA}^{1)}$ & $\mathrm{AB}$ & $\mathrm{BA}$ & BB \\
\hline FT1 & Satt365 & FT2 & E7M19Mo190 & 53.2 & 10.26 & -3.69 & -2.52 & 79.6 & 31.8 & $<0.000$ & 57.3 & 69.7 & 41.8 & 44.1 \\
\hline FT1 & $\mathrm{tt} 365$ & FT3 & & 53.0 & 10.17 & 2.44 & 2.21 & 74.1 & 19.0 & & 67.8 & 58.5 & 43.1 & 42.6 \\
\hline$F T 2$ & E7M19Mo190 & FT3 & E6M22mi400 & 53.2 & -4.02 & & -2.50 & 19.0 & 7.5 & & 49.8 & 48.7 & 62.8 & 51.7 \\
\hline$H A V 1$ & Satt365 & $H A V 3$ & & 130.0 & 12.63 & -4 . & & 56.5 & & & 140.5 & 144.7 & 110.0 & 124.7 \\
\hline$R P 1$ & E7M19mo160 & $R P 2$ & Satt286 & 79.7 & 3.85 & 3.89 & -1.97 & 21.3 & 4.5 & 0.035 & 85.4 & 81.6 & 81.7 & 69.9 \\
\hline VIS1 & $D t 1$ & VIS5 & E12M24Mi550 & 0.54 & -0.10 & -0.04 & -0.043 & 25.1 & 6.7 & 0.011 & 0.36 & 0.53 & 0.64 & 0.64 \\
\hline WAS4 & $D t 1$ & WAS5 & A586 & 2.32 & 0.03 & -0.01 & -0.015 & 16.6 & 5.3 & 0.023 & 2.32 & 2.37 & 2.30 & 2.29 \\
\hline SWE2 & M6_31 & SWE3 & & 13.1 & 0.56 & 0.60 & 0.40 & 16.4 & 4.9 & & 14.7 & 12.7 & 12.8 & 12.4 \\
\hline SWH2 & Satt518 & SWH6 & Satt072 & 10.3 & 0.44 & 0.66 & -0.60 & 15.1 & 9.8 & 0.002 & 10.8 & 10.7 & 11.2 & 8.6 \\
\hline
\end{tabular}

The model formula of this analysis was described in materials and methods of the text. Genotypes of each QTL were determined by the nearest marker shown in Table 2. All coefficients in the model denote the following: $\mu$ : mean of phenotypic value, $a$ : additive effect of QTL1, $b$ : additive effect of QTL2, $i_{A B}$ : effect of interaction between QTL1 and 2. The interaction between two QTLs was confirmed by $F$-test. These results correspond to that of two-way classification ANOVA.

1) average phenotypic value based on each classified genotype.

AA: QTL1, QTL2 Misuzudaizu allele

AB: QTL1 Misuzudaizu allele, QTL2 Moshidou Gong 503 allele BA: QTL1 Moshidou Gong 503 allele, QTL2 Misuzudaizu allele BB: QTL1, QTL2 Moshidou Gong 503 allele 
VIS1 and VIS5, WAS4 and WAS5, SWE2 and SWE3, and, SWH2 and SWH6.

\section{Discussion}

In our study, a linkage map of soybean based on a RIL population could be constructed, which showed linkage groups corresponding to the soybean chromosome number $(n=20)$. Furthermore, many loci could be detected as QTLs for reproductive development and seed quality traits. Compared with previous maps, this map was estimated to provide $80 \%$ to $90 \%$ of the coverage of the soybean genome. Although most markers showed normal segregation ratios, a few markers exhibited segregation distortions. We compared these regions with a $F_{2}$ linkage map that showed a large segregation distortion region on linkage group $\mathrm{J}$ (Yamanaka et al. 2003). No marker on LG J showed segregation distortion in the RIL population. However, markers in the region of LG L (Satt156-GM267) were commonly skewed in both $\mathrm{F}_{2}$ and RIL populations. Although, we could not determine the reasons for the disappearance of this large segregation distortion region of $L G \mathrm{~J}$, in rice, segregation distortion changed with the generations analyzed (Harushima et al. 1996).

Flowering time and maturity $\left(r^{2}=0.73\right)$, and maturity and reproductive period $\left(r^{2}=0.79\right)$ displayed high correlation coefficients. Among the detected QTLs related to these traits, the same gene might underlie $F T 1, H A V 1$ and $R P 2$ that were detected proximally in the same region of LG C2. Similarly, we considered that FT2 and HAV3 (on LG O), $H A V 2$ and RP1 (LG C1) and RP3 and HAV4 (LG A2) were associated with each other by the common genes, respectively. These facts indicate that the flowering time and reproductive period are controlled by a differential pathway. All the QTLs for the flowering time, maturity, and reproductive period corresponded to known QTL loci (Yamanaka et al. 2001, Orf et al. 1999a).

Unexpected correlation between flowering time and germination rate $\left(r^{2}=0.5\right)$ was observed. RAS1, FTI occurred at the same location (on LG C2), and in this region, some QTLs of other traits (SWH1,WAS1) were also located. This result shows that several genes were closely linked and/ or that there was a pleiotropic gene in this region. In other studies using a large genomic library of soybean, it was suggested that this region might be characterized by a large physical distance compared with the genetic distance (Xia personal communication).

Imbibition is the first step in the successive processes associated with the breaking of seed dormancy. Seed hardness is controlled by the seed coat character. In a previous study, it was showed that the $I$ locus which was defined based on a qualitative traits related to the hilum color and seed pigmentation controlled by the chalcone synthase (CHS) gene family, was the QTL with the highest correlation with seed hardness (Todd et al. 1996, Keim et al. 1990). The most effective QTL for seed hardness detected in this study was located in the region near the $T$ locus (RAS1). Toda et al. (2002) showed that the $T$ locus encodes the flavonoid 3'-hydoxylase gene which controls the pubescence color of stem. $T$ and $I$ cooperate for the hilum color and seed pigmentation and may be associated with seed hardness and other seed characters.

Regarding the QTLs for seed weight, only two QTLs were detected over a period of two years. Seed weight is very readily affected by environmental conditions, and previous data showed that polygenic influence resulted in a large number of QTLs (Lee et al. 1996, Brummer et al. 1997). Compared with the previous study, SWH3 and SWE4 on LG B2, SWH1 on LG C2, SWE3 on LG E, SWH6 on LG $\mathrm{F}$, and $S W H 2$ and $S W E 5$ on LG K might be identical with the QTLs previously reported (Mansur et al. 1996, Orf et al. 1999a, Hoeck et al. 2003). The other QTLs detected on LG $\mathrm{D} 1 \mathrm{~b}, \mathrm{H}, \mathrm{I}$ and $\mathrm{M}$ were unique in this population.

Brummer et al. (1997) classified QTLs into two types: environmentally stable QTLs, which were detected in different environments, and environmentally sensitive QTLs, which were found in only one environment. The environmentally stable QTLs may be suitable for marker-assisted selection for breeding programs. Additionally, many epistastic interactions between QTLs were observed in this population. For marker-assisted selection for breeding, the simultaneous application of many markers, in taking account of epistasis, will lead to a highly effective selection of phenotypes.

For further analysis of these QTLs, fine mapping and map-based cloning of each QTL are necessary. The mapping of QTLs in a segregation population shows a limited resolution, because QTLs can be mapped with a precision of about $10-20 \mathrm{cM}$. Because the accuracy of QTL analysis depends on the heritability of each QTL and size of population, an additional strategy is required to determine more precisely the position of QTLs. The use of near-isogenic lines (NILs) that are developed by backcrossing and differ at a single QTL can be an effective approach for the fine mapping and characterization of individual loci. However, this method is time-consuming and laborious for the development of NILs in soybean. Residual heterozygous lines (RHLs) derived from recombinant inbred lines display a segregated region in a genome where a certain QTL is located. RHLs are isogenic at the majority of the loci in the genome. Heterozygous region can lead to segregation of a phenotypic trait controlled by a single genetic region in the progeny of this family (Yamanaka et al. unpublished data).

Although Tasma et al. (2003) mapped flowering time gene homologs of Arabidopsis in soybean, most of them were not associated with $E$ loci. Therefore, further analyses should be performed to identify QTLs for flowering time. We have developed RHLs for FT1, FT2 and FT3 and fine mapping of these QTLs is underway. Additional RHLs for other QTLs related to important traits, for example seed components, will be developed in the near future. 


\section{Acknowledgements}

This study was partly supported by the Programme for the Promotion of Basic Research Activities for Innovative Biosciences, and by Takano Life Science Research Foundation.

\section{Literature Cited}

Basten,C.J., B.S.Weir and Z.B.Zeng (2001) QTL Cartographer, Version 2.0. Department of Statistics, North Carolina State University, Raleigh, USA.

Brummer,E.C., G.L.Graef, J.Orf, J.R.Wilcox and R.C.Shoemaker (1997) Mapping QTL for seed protein and oil content in eight soybean populations. Crop Sci. 37: 370-378.

Cregan, P.B., T. Jarvik, A.L. Bush, R.C. Shoemaker, K.G. Lark, A.L.Kahler, N.Kaya, T.T.Vantoai, D.G.Lohnes, J.Chung and J.E.Specht (1999) An integrated genetic linkage map of the soybean genome. Crop Sci. 39: 1464-1490.

Diers, B.W., P.Keim, W.R.Fehr and R.C.Shoemaker (1992) RFLP analysis of soybean seed protein and oil content. Theor. Appl. Genet. 83: 608-612.

Gomez,K.A. and A.A.Gomez (1984) Statistical Procedures for Agricultural Research. John Wiley \& Sons Inc, New York. 680p.

Harushima,Y., N.Kurata, M.Yano, Y.Nagamura, T.Sasaki, Y.Minobe and M.Nakagahra (1996) Detection of segregation distortion region in an indica-japonica rice cross using a high-resolution molecular map. Theor. Appl. Genet. 92: 145-150.

Hayashi,M., A.Miyahara, S.Sato, T.Kato, M.Yoshikawa, M.Taketa, M.Hayashi, A.Pedrosa, R.Onda, H.Imaizumi-Anraku, A.Bachmair, N.Sandal, J.Stougaard, Y.Murooka, S.Tabata, S. Kawasaki, M.Kawaguchi and K.Harada (2001) Construction of a genetic linkage map of the model legume Lotus japonicus using an intraspesific $\mathrm{F}_{2}$ population. DNA Res. 8: 301-310.

Hoeck,J.A., W.R.Fehr, R.C.Shoemaker, G.A.Welke, S.L.Johnson and S.R.Cianzio (2003) Molecular marker analysis of seed size in soybean. Crop Sci. 43: 68-74.

Hossain, K.G., H.Kawai, M.Hayashi, M.Hoshi, N. Yamanaka and K.Harada (2000) Characterization and identification of (CT)n microsatellites in soybean using sheared genomic libraries. DNA Res. 7: 103-110.

Keim,P., D.W.Diers and R.C.Shoemaker (1990) Genetic analysis of soybean hard seededness with molecular markers. Theor. Appl. Genet. 79: 465-469.

Lander,E.S. and D.Botstein (1989) Mapping mendelian factors underlying quantitative traits using RFLP linkage maps. Genetics 121: 185-199.

Lark, K.G., J.Orf and L.M.Mansur (1994) Epistatic expression of quantitative trait loci (QTL) in soybean [Glycine $\max (\mathrm{L}$. Merr.] determined by QTL association with RFLP alleles. Theor. Appl. Genet. 88: 486-489.

Lark,K.G., K.Chase, F.Adler, L.M.Mansur and J.H.Orf (1995) Interactions between quantitative trait loci in soybean in which trait variation at one locus is conditional upon a specific allele at another. Proc. Natl. Acad. Sci. USA 92: 4656-4660.

Lee, S.H., M.A. Bailey, M.A.R. Mian, T.E.Carter Jr., E.R. Shipe, D.A. Ashley, W.A. Parrott, R.S. Hussey and H.R. Boerma (1996) RFLP loci associated with soybean seed protein and oil content across populations and locations. Theor. Appl. Genet. 93: 649-657.

Lincoln, S.E., M.J.Daly and E.S.Lander (1993) MAPMAKER/EXP.
Whitehead Institute of Biomedical Research, Cambridge, Massachusetts.

Mansur,L.M., K.G.Lark, H.Kross and A.Oliveira (1993) Interval mapping of quantitative trait loci for reproductive, morphological, and seed traits of soybean (Glycine max L.). Theor. Appl. Genet. 86: 907-913.

Mansur,L.M., J.H.Orf, K.Chase, T.Jarvik, P.B.Cregan and K.G.Lark (1996) Genetic mapping of agronomic traits using recombinant inbred lines of soybean. Crop Sci. 36: 1327-1336.

Maughan,P.J., M.A.Saghai Maroof and G.R.Buss (1996) Molecularmarker analysis of seed-weight: genomic locations, gene action, and evidence for orthologous evolution among three legume species. Theor. Appl. Genet. 93: 574-579.

Murray,M.G. and W.F.Thompson (1980) Rapid isolation of highmolecular-weight plant DNA. Nucleic Acids Res. 8: 4321-4325.

Orf,J.H., K.Chase, T.Jarvik, L.M.Mansur, P.B.Cregan, F.R.Adler and K.G.Lark (1999a) Genetics of soybean agronomic traits: I. Comparison of three related recombinant inbred populations. Crop Sci. 39: 1642-1651.

Orf,J.H., K.Chase, F.R.Adler, L.M.Mansur and K.G.Lark (1999b) Genetics of soybean agronomic traits: II. Interactions between yield quantitative trait loci in soybean. Crop Sci. 39: 1652-1657.

Song,Q.J., L.F.Marek, R.C.Shoemaker, K.G.Lark, V.C.Concibido, X.Delannay, J.E.Specht and P.B.Cregan (2004) A new integrated genetic linkage map of the soybean. Theor. Appl. Genet. 109: 122-128.

Tajuddin, T., S.Watanabe, K.Harada and S.Kawano (2002) Application of NIR transmittance spectroscopy to the estimation of protein and lipid contents in single seeds of soybean recombinant inbred lines for quantitative trait loci (QTL) analysis. J. Near Infrared Spectrosc. 10: 315-325.

Tajuddin, T., S.Watanabe, N.Yamanaka and K.Harada (2003) Analysis of quantitative trait loci for protein and lipid contents in soybean seeds using recombinant inbred lines. Breed. Sci. 53: 133-140.

Tasma,I.M. and R.C.Shoemaker (2003) Mapping flowering time gene homologs in soybean and their association with maturity $(E)$ loci. Crop Sci. 43: 319-328.

Toda,K., D.Yang, N.Yamanaka, S.Watanabe, K.Harada and R.Takahashi (2002) A single base deletion in soybean flavonoid 3'-hydroxylase gene is associated with gray pubescence color. Plant Molecular Biology 50: 187-196.

Todd,J.J. and L.O.Vodkin (1996) Duplication that suppress and deletions that restore expression from a chalcone synthase multigene family. Plant cell. 8: 687-699.

Vos,P., R.Hogers, M.Bleeker, M.Reijans, T.Lee, M.Hornes, A.Frijters, J.Pot, J.Peleman, M.Kuiper and M.Zabeau (1995) AFLP: a new technique for DNA fingerprinting. Nucleic Acids Res. 23: 4407-4414.

Yamanaka,N., Y.Nagamura, Y.Tsubokura, K.Yamamoto, R.Takahashi, H.Kouchi, M.Yano, T.Sasaki and K.Harada (2000) Quantitative trait locus analysis of flowering time in soybean using a RFLP linkage map. Breed. Sci. 50: 109-115.

Yamanaka, N., S. Ninomiya, M. Hoshi, Y. Tsubokura, M. Yano, Y.Nagamura, T.Sasaki and K.Harada (2001) An informative linkage map of soybean reveals QTLs for flowering time, leaflet morphology and region of segregation distortion. DNA Res. 8: $61-72$.

Zeng,Z.B. (1993) Theoretical basis for separation of multiple linked gene effects in mapping quantitative trait loci. Proc. Natl. Acad. Sci. USA 90: 10972-10976. 